\title{
Evaluation of Comprehensive Cultivation Model of Undergraduate and Master Based on 2-tuple Linguistic Information
}

\author{
Ming Li, Yanxin Lu
}

\begin{abstract}
The cultivation of innovative talents in colleges and universities is a long-term and complex systematic project. It includes the systematic reform of the cultivation concept, the re-orientation of training objectives, the planning and optimization of discipline and specialty, the reform of training mode and the optimization of curriculum structure. Many colleges and universities have advanced practices. These successful experiences will serve as important references for other colleges and universities. In order to select the most suitable integrated training mode, this paper proposes an integrated training mode evaluation method based on 2-tuple linguistic model. First, the evaluation index system is constructed from the aspects of cohesion of theoretical courses, cohesion of practical links, coherence of academic research, coherence of international training and support of personalized training. Secondly, the evaluation method of 2-tuple linguistic model is proposed. Finally, a hypothetical illustrating example is given to illustrate the proposed method.
\end{abstract}

Index Terms-Quality Assessment, 2-tuple linguistic information, Comprehensive cultivation model.

\section{INTRODUCTION}

Educating people is the fundamental task of colleges and universities [1]. China's national strategy of rejuvenating the country through science and education is implemented gradually. The independent innovation is the foundation of building a country and the road of strengthening the country. The cultivation of innovative talents in colleges and universities is a long-term and complex systematic project. It includes the systematic reform of the cultivation concept, the re-orientation of training objectives, the planning and optimization of discipline and specialty, the reform of training mode and the optimization of curriculum structure [2].

According to the requirements of the state and society, referring to the experience of talent cultivation in first-class universities at home and abroad, and according to the orientation of the school's development, it is necessary to reconstruct the undergraduate teaching system of research universities. For the training of undergraduate and postgraduate talents at different levels, more clear and higher requirements are put forward. Discipline construction needs

Ming Li, School of Economics and Management, China University of Petroleum-Beijing, Beijing, China.

Yanxin Lu, College of Geophysics, China University of Petroleum-Beijing, Beijing, China. the support of excellent students. The integrated curriculum system will attract high-quality students and let excellent students get in touch with postgraduate courses early, which plays an important role in the development of personalization. Therefore, many universities have carried out the reform of the training mode of the integration of comprehensive cultivation model of undergraduate and master [3]. In each training mode, the emphasis is different. We need to be able to evaluate the training mode of each school from many aspects, so as to find out the characteristics of each training mode, and help to select the most suitable training mode as a reference. Therefore, this paper first constructs the evaluation index system of the training mode, and on this basis. Then the 2-tuple linguistic model is used to process the evaluation information of the candidate training mode. Finally, a hypothetical example is given to illustrate the proposed method.

\section{INDICATOR SYSTEM}

The assessment of the comprehensive training model includes the following aspects: the scientific and feasibility of the training model, the satisfaction of the needs of the country, society, and school target.

In order to build a scientific and feasible training model, it needs the smooth convergence between different stages. Then we can explore the systematic and scientific training mode by analyzing students' knowledge structure and quality.

The key to the "Comprehensive Cultivation Model" is combination of undergraduate training and postgraduate training to avoid duplication effectively, improve teaching efficiency, and optimize the curriculum system to highlight innovation, strengthen foundation, and cultivate individuality of students.

According to in-depth investigation and research, the following five quality evaluation indicators are proposed.

(1) Cohesiveness of theoretical courses

It is used to evaluate the cohesion between graduate courses and undergraduate courses. The contents of undergraduate courses are wider, while those of postgraduate courses are deeper. The undergraduate major of graduate students may be different. The theoretical courses that they have learned are not entirely consistent, even if the theoretical courses are consistent, the specific content and depth of teaching are not entirely the same. Therefore, when designing the integrated training mode of undergraduate and graduate students, the course of undergraduate and graduate students 
needs to be able to link up and cannot appear more repetitive content. For some graduates, they can learn some undergraduate course independently.

(2) Cohesiveness of practice

This index is to evaluate the correlation between graduate practice and undergraduate practice. Practice teaching is an important part of personnel training. The purpose of practice training undergraduates and postgraduates is different. Undergraduates' practice is more inclined to understand. The practice of graduate students pays more attention to the support of research work. In the integrated training mode, we need to be able to build on the basis of undergraduate practice, improve the difficulty and depth, and avoid the disconnection with undergraduate practice. At the same time, in the design of practical links for graduate students, we need to be able to fully consider the characteristics of students' different professional backgrounds. For example, we can supplement the content of undergraduate practice links through counseling and extra-curricular guidance.

(3) Coherence in academic research

Academic research has expanded from postgraduate to undergraduate training. When undergraduates are freshmen, they can apply for scientific and technological innovation projects to conduct preliminary scientific research training. Therefore, the optimization of undergraduate training program should consider the training objectives, direction, orientation and requirements of graduate students. The contents of academic research are incorporated into the training program. Moreover, orientation of undergraduate students' academic training needs be clear according to the requirements of graduate training. In the undergraduate courses related to the direction of postgraduate research, we should pay attention to the cultivation of academic quality. Academic research needs to be reflected in many aspects of undergraduate training

(4) Coherence of international training

High-level research needs international cooperation. The cultivation of high-quality talents also needs an international perspective. Therefore, both undergraduates and postgraduates need to be nationalized. In the process of internationalization, we should pay attention to the coherence of country, school and specialty. In other words, foreign schools or institutions recommended to students need to be able to provide undergraduate education and postgraduate research. Through long-term cooperation, we can carry out more effective internationalization training, which is also conducive to improving the competitiveness of students.

(5) Supportiveness of individualized training

In the integrated training mode, it is necessary to fully meet the needs of students' personalized development. There are differences among students themselves, and the background of undergraduate education is different. So, the training mode needs to be able to support the requirements of students' personalized development. In the setting of training mode, we need to be able to provide instructive choices, provide different types and different levels of curriculum combination to support different directions of development. At the same time, in the designing of specific curriculum content, we should also be able to fully take into account the individual characteristics of students in both breadth and depth.

\section{THE EVALUATION MODEL OF INTEGRATED TRAINING MODE BASED ON 2-TUPLE LINGUISTIC INFORMATION}

According to the research object of this model, there is some uncertainty about the quality evaluation of the comprehensive cultivation mode of this research. Therefore, the evaluation model of integrated training mode based on 2-tuple linguistic information is given in the section [4-5].

Firstly, experts are invited to evaluate on the training mode by using the predefined linguistic terms $S$. Next, expert evaluation information are combined by the arithmetic mean operator of 2-tuple linguistic model. Finally, the evaluation result can be derived.

The evaluation objects set is represented by $A=\left\{A_{i} \mid i=1,2, \ldots, M\right\}$, the evaluation indicators set is defined as $B=\left\{B_{j} \mid j=1,2, \ldots, N\right\}$, and the evaluation experts set is represented by $C=\left\{C_{l} \mid l=1,2, \ldots, L\right\}$.

\section{A. Obtain evaluation matrix of each expert}

For all the experts participating in the evaluation, the evaluation of each evaluation index of all evaluation objects is expressed in the form of linguistic terms. These linguistic terms are transformed into the 2-tuple linguistic forms [4-5].

The matrix $D^{(l)}$ obtained is as follows:

$$
\begin{gathered}
D^{(l)}=\left[\left(d_{i j}^{l}, 0\right)\right]_{M \times N}=\left[\begin{array}{cccc}
\left(d_{11}^{l}, 0\right) & \left(d_{12}^{l}, 0\right) & \cdots & \left(d_{l N}^{l}, 0\right) \\
\left(d_{21}^{l}, 0\right) & \left(d_{22}^{l}, 0\right) & \cdots & \left(d_{2 N}^{l}, 0\right) \\
\cdots & \cdots & \cdots & \cdots \\
\left(d_{M 1}^{l}, 0\right) & \left(d_{M 2}^{l}, 0\right) & \cdots & \left(d_{M N}^{l}, 0\right)
\end{array}\right] \\
\left(d_{i j}^{l} \in S, i=1,2, \cdots, M ; l=1,2, \cdots, L ; j=1,2, \cdots, N\right)
\end{gathered}
$$

\section{B. Acquire index weight matrix of each expert}

For all $L$ experts participating in the evaluation, each evaluation index is evaluated by linguistic terms and these linguistic terms are also transformed into the form of 2-tuple linguistic model [4-5]. The index importance matrix $V$ is as follows :

$$
\begin{array}{r}
V=\left[\left(v_{l j}, 0\right)\right]_{L \times N}=\left[\begin{array}{cccc}
\left(v_{l 1}, 0\right) & \left(v_{l 2}, 0\right) & \cdots & \left(v_{I N}, 0\right) \\
\left(v_{21}, 0\right) & \left(v_{22}, 0\right) & \cdots & \left(v_{2 N}, 0\right) \\
\cdots & \cdots & \cdots & \ldots \\
\left(v_{l l}, 0\right) & \left(v_{l 2}, 0\right) & \cdots & \left(v_{l N}, 0\right)
\end{array}\right] \\
\left(v_{l j} \in S ; l=1,2, \cdots, L ; j=1,2, \cdots, N\right)
\end{array}
$$

\section{Calculate comprehensive evaluation matrix}

The comprehensive evaluation matrix of $L$ experts is obtained by synthesizing all evaluation results with 2-tuple linguistic model arithmetic mean operator [4-5], the indicator importance matrix $D$ is as follows:

$$
\begin{gathered}
D=\left[\left(d_{i j}, b_{i j}\right)\right]_{M \times N}=\left[\begin{array}{cccc}
\left(d_{11}, \beta_{11}\right) & \left(d_{12}, \beta_{12}\right) & \cdots & \left(d_{I N}, \beta_{1 \mathrm{~N}}\right) \\
\left(d_{21}, \beta_{21}\right) & \left(d_{22}, \beta_{22}\right) & \cdots & \left(d_{2 N}, \beta_{2 \mathrm{~N}}\right) \\
\cdots & \cdots & \cdots & \cdots \\
\left(d_{M 1}, \beta_{\mathrm{M} 1}\right) & \left(d_{M 2}, \beta_{\mathrm{M} 2}\right) & \cdots & \left(d_{M N}, \beta_{M N}\right)
\end{array}\right] \\
\left(d_{i j}, \beta_{i j}\right)=\Delta\left(\frac{1}{L} \sum_{l=1}^{L} \Delta^{-1}\left(d_{i j}^{l}, 0\right)\right) \\
\left(d_{i j} \in S, \beta_{i j} \in[-0.5,0.5) ; i=1,2, \cdots, M ; j=1,2, \cdots, N\right)
\end{gathered}
$$


World Journal of Research and Review (WJRR)

ISSN:2455-3956, Volume-8, Issue-4, April 2019 Pages 22-25

\section{Obtain comprehensive weight matrix}

The 2-tuple linguistic model arithmetic mean operator [4-5] is adopted to synthesize the importance degree of all indexes, and the comprehensive index weight matrix $\bar{V}$ is obtained:

$$
\begin{gathered}
\bar{V}=\left[\left(\mathrm{v}_{j}, \alpha_{j}\right)\right]_{l \times N}=\left[\left(v_{1}, \alpha_{1}\right),\left(v_{2}, \alpha_{2}\right), \cdots,\left(v_{N}, \alpha_{N}\right)\right] \\
\left(v_{j}, \alpha_{j}\right)=\Delta\left(\frac{1}{L} \sum_{l=1}^{L} \Delta^{-1}\left(v_{i j}, 0\right)\right) \\
\left(v_{i j} \in S, \alpha_{j} \in[-0.5,0.5) ; l=1,2, \cdots, L ; j=1,2, \cdots, N\right)
\end{gathered}
$$

\section{E. Calculate the weighted average result}

The weighted average result of evaluation objects is calculated by $[4-5]$ :

$$
\begin{gathered}
\left(s_{i}, g_{i}\right)=\Delta\left(\frac{\sum_{j=1}^{N} \Delta^{-1}\left(v_{j}, \alpha_{j}\right) \times \Delta^{-1}\left(d_{i j}, \beta_{i j}\right)}{\sum_{j=1}^{N} \Delta^{-1}\left(v_{j}, \alpha_{j}\right)}\right) \\
(i=1,2, \cdots, M)
\end{gathered}
$$

\section{ILLUSTRATE EXAMPLE}

In the section, the proposed method is used to explain the model. Suppose that there are three training candidate models $M_{1}, M_{2}$ and $M_{3}$ to be evaluated. Suppose that three experts are invited in the evaluation including $C_{1}, C_{2}$ and $C_{3}$. The five quality evaluation indicators are denoted by $I_{1}, I_{2}, I_{3}, I_{4}, I_{5}$

Based on the five types of integrated quality evaluation indexes: $S=\left\{s_{0}=V L, s_{1}=R L, s_{2}=G, s_{3}=R H, s_{4}=V H\right\}$, which represents \{Very Low, Low, Relatively Low, General, Relatively High, Very High\}.

Three experts are invited to evaluate on the training mode by using the predefined linguistic terms. The three experts' evaluation results of the objects scores are shown in Tables $1-3$, and their evaluation results on the importance of the indicators is listed in Table 4.

Table 1. Evaluation of candidates given by expert $\mathrm{C}_{1}$

\begin{tabular}{cccccc}
\hline & $I_{1}$ & $I_{2}$ & $I_{3}$ & $I_{4}$ & $I_{5}$ \\
\hline$M_{1}$ & $\mathrm{RL}$ & $\mathrm{G}$ & $\mathrm{RL}$ & $\mathrm{G}$ & $\mathrm{RH}$ \\
$M_{2}$ & $\mathrm{VH}$ & $\mathrm{RL}$ & $\mathrm{VH}$ & $\mathrm{RL}$ & $\mathrm{L}$ \\
$M_{3}$ & $\mathrm{VH}$ & $\mathrm{H}$ & $\mathrm{G}$ & $\mathrm{L}$ & $\mathrm{VL}$ \\
\hline
\end{tabular}

Table 2. Evaluation of candidates given by expert $\mathrm{C}_{2}$

\begin{tabular}{cccccc}
\hline & $I_{1}$ & $I_{2}$ & $I_{3}$ & $I_{4}$ & $I_{5}$ \\
\hline$M_{1}$ & $\mathrm{~L}$ & $\mathrm{G}$ & $\mathrm{RL}$ & $\mathrm{L}$ & $\mathrm{RH}$ \\
$M_{2}$ & $\mathrm{VL}$ & $\mathrm{H}$ & $\mathrm{H}$ & $\mathrm{H}$ & $\mathrm{RL}$ \\
$M_{3}$ & $\mathrm{H}$ & $\mathrm{RL}$ & $\mathrm{RH}$ & $\mathrm{G}$ & $\mathrm{VL}$ \\
\hline
\end{tabular}

Table 3. Evaluation of candidates given by expert $\mathrm{C}_{3}$

\begin{tabular}{cccccc} 
& $I_{1}$ & $I_{2}$ & $I_{3}$ & $I_{4}$ & $I_{5}$ \\
\hline$M_{1}$ & $\mathrm{RL}$ & $\mathrm{RH}$ & $\mathrm{L}$ & $\mathrm{G}$ & $\mathrm{RL}$ \\
$M_{2}$ & $\mathrm{H}$ & $\mathrm{RL}$ & $\mathrm{H}$ & $\mathrm{H}$ & $\mathrm{L}$ \\
$M_{3}$ & $\mathrm{G}$ & $\mathrm{G}$ & $\mathrm{RH}$ & $\mathrm{L}$ & $\mathrm{VH}$ \\
\hline
\end{tabular}

Table 4. Experts' evaluation on the importance of indicators

\begin{tabular}{cccccc} 
& $I_{1}$ & $I_{2}$ & $I_{3}$ & $I_{4}$ & $I_{5}$ \\
\hline $\mathrm{C}_{1}$ & $\mathrm{G}$ & $\mathrm{RL}$ & $\mathrm{VH}$ & $\mathrm{G}$ & $\mathrm{H}$ \\
$\mathrm{C}_{2}$ & $\mathrm{H}$ & $\mathrm{VH}$ & $\mathrm{L}$ & $\mathrm{RL}$ & $\mathrm{VL}$ \\
$\mathrm{C}_{3}$ & $\mathrm{RH}$ & $\mathrm{G}$ & $\mathrm{L}$ & $\mathrm{H}$ & $\mathrm{VH}$ \\
\hline
\end{tabular}

The detailed evaluation steps are conducted as follows:

\section{A. Obtain evaluation matrix of each expert}

Convert evaluation results in Tables 1-3 into a 2-tuple linguistic evaluation matrix:

$$
\begin{gathered}
D^{(I)}=\left[\begin{array}{l}
\left(s_{2}, 0\right)\left(s_{3}, 0\right)\left(s_{2}, 0\right)\left(s_{1}, 0\right)\left(s_{5}, 0\right) \\
\left(s_{6}, 0\right)\left(s_{4}, 0\right)\left(s_{4}, 0\right)\left(s_{4}, 0\right)\left(s_{2}, 0\right) \\
\left(s_{6}, 0\right)\left(s_{2}, 0\right)\left(s_{5}, 0\right)\left(s_{3}, 0\right)\left(s_{0}, 0\right)
\end{array}\right] \\
D^{(2)}=\left[\begin{array}{l}
\left(s_{1}, 0\right)\left(s_{3}, 0\right)\left(s_{2}, 0\right)\left(s_{1}, 0\right)\left(s_{5}, 0\right) \\
\left(s_{0}, 0\right)\left(s_{4}, 0\right)\left(s_{4}, 0\right)\left(s_{4}, 0\right)\left(s_{2}, 0\right) \\
\left(s_{4}, 0\right)\left(s_{2}, 0\right)\left(s_{5}, 0\right)\left(s_{3}, 0\right)\left(s_{0}, 0\right)
\end{array}\right] \\
D^{(3)}=\left[\begin{array}{l}
\left(s_{2}, 0\right)\left(s_{5}, 0\right)\left(s_{1}, 0\right)\left(s_{3}, 0\right)\left(s_{2}, 0\right) \\
\left(s_{4}, 0\right)\left(s_{2}, 0\right)\left(s_{4}, 0\right)\left(s_{4}, 0\right)\left(s_{1}, 0\right) \\
\left(s_{3}, 0\right)\left(s_{3}, 0\right)\left(s_{5}, 0\right)\left(s_{1}, 0\right)\left(s_{6}, 0\right)
\end{array}\right]
\end{gathered}
$$

\section{B. Acquire index weight matrix of each expert}

Convert evaluation result in Table 4 into a 2-tuple linguistic weight matrix:

$$
V=\left[\begin{array}{l}
\left(v_{3}, 0\right)\left(v_{2}, 0\right)\left(v_{6}, 0\right)\left(v_{3}, 0\right)\left(v_{4}, 0\right) \\
\left(v_{4}, 0\right)\left(v_{6}, 0\right)\left(v_{1}, 0\right)\left(v_{2}, 0\right)\left(v_{0}, 0\right) \\
\left(v_{5}, 0\right)\left(v_{3}, 0\right)\left(v_{1}, 0\right)\left(v_{4}, 0\right)\left(v_{6}, 0\right)
\end{array}\right]
$$

\section{Calculate comprehensive evaluation matrix}

The comprehensive evaluation matrix is obtained by using Eq (3).

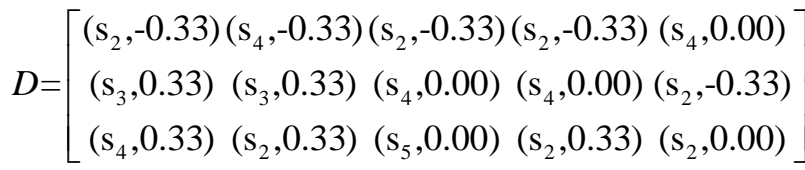

\section{Obtain comprehensive weight matrix}

The comprehensive weight matrix is obtained by Eq (4).

$\bar{V}=\left[\left(s_{4}, 0.00\right),\left(s_{4},-0.33\right),\left(s_{3},-0.33\right),\left(s_{3}, 0.00\right),\left(s_{3}, 0.33\right)\right]$

\section{E. Calculate the weighted average result}

The weighted average result of evaluation objects is obtained by Eq (5).

$$
\left(\hat{s}_{i}, \hat{\alpha}_{i}\right)=\left[\left(\mathrm{s}_{3},-0.43\right),\left(\mathrm{s}_{3}, 0.23\right),\left(\mathrm{s}_{3}, 0.17\right)\right],(i=1,2,3)
$$

\section{CONCLUSIONS}

This paper proposes an integrated training mode evaluation method based on 2-tuple linguistic model. Firstly, the evaluation index system is constructed from the aspects of cohesion of theoretical courses, cohesion of practical links, coherence of academic research, coherence of international training and support of personalized training. Then the evaluation method of 2-tuple linguistic model is presented. Finally, a hypothetical illustrating example is given to 
illustrate the method. Through the method proposed in this paper, it will be helpful to select the best reference training mode from many aspects and from multiple integrated training modes.

\section{REFERENCES}

[1] Yuan chuan, dong zefang, ai xiaoping, \& zhang hui. (2012). What is the choice between "generalists" or "specialists"? Also on the value orientation of higher education purpose in the period of social transformation. Modern education management, (9), (5-9).

[2] Ma yanxiang, \& cai zhonghong. (2009). On the reform and trend of talent training model in universities and colleges. Journal of lanzhou jiaotong university, 5 .

[3] Liu yandong. (2012). Deepening the reform of higher education and taking the connotative development path with improving quality as the core. Seeking truth, 10 (3)

[4] Herrera, f., \& martínez, 1. (2000). A 2-tuple fuzzy linguistic representation model for computing with words. Ieee transactions on fuzzy systems, 8(6), 746-752.

[5] Herrera, f., \& martinez, 1. (2001). The 2-tuple linguistic computational model: advantages of its linguistic description, accuracy and consistency. International journal of uncertainty, fuzziness and knowledge-based systems, 9(supp01), 33-48. 